\title{
Studies of Free Fluctuations of the Sea of Azov Level Arising After the Termination of Prolonged Wind Effect
}

\author{
V.A. Ivanov, L.V. Cherkesov, T.Ya. Shul'ga \\ Marine Hydrophysical Institute, Russian Academy of Sciences, Sevastopol, \\ Russian Federation \\ e-mail: shulgaty@mail.ru
}

\begin{abstract}
Physical regularities of liquid free fluctuations in the Sea of Azov arising after constant wind has stopped, are analyzed. The simulations are done by a nonlinear three-dimensional sigma-coordinate model. Its application permits to define spatial characteristics of seiche-like fluctuations, arrangement of nodal lines and velocities of the arising currents. The seiche-like fluctuations' amplitudes and periods are studied for the stations located on the coast and the points of the Azov Sea deep central part. The performed studies result in revealing the fact that the maximum seiche-like oscillations in the coastal zone are comparable to the scales of a storm surge phenomena. At that the level the free fluctuations' heights in the open sea makes $50-89 \%$ of those along the coastline. The amplitude of the sea level free oscillations in the deep sea is by $1.2-2$ times smaller than those at the coastal stations. The results of the numerical experiments testify to the fact that free fluctuations attenuate faster in the central part of the sea than in the coastal regions. Being effected by a stable wind, the sea level changes in the Sea of Azov coastal regions twice exceed the maximum values of the level deviations in the sea central part. In the central part at seiche-like fluctuations, the currents' maximum velocities exceed the velocities of the gale-induced stationary currents by $21 \%$. It is found that the seiches make essential contribution to variability of the currents' velocities. At that the level free fluctuations attenuate faster than the amplitudes of currents' velocities.
\end{abstract}

Keywords: three-dimensional nonlinear model, free fluctuations of liquid, seiche, stationary currents, surge phenomena processes, nodal lines.

DOI: 10.22449/1573-160X-2015-2-14-23

(c) 2015, V.A. Ivanov, L.V. Cherkesov, T.Ya. Shul'ga

(c) 2015, Physical Oceanography

In the Sea of Azov basin free wave (seiche-like) fluctuations of level, occurring after the termination of atmospheric perturbations, are constantly observed. Besides, in the narrow spots of coastal boundaries current velocities reach $1.5 \mathrm{~m} / \mathrm{s}$, and wave heights $-0.8 \mathrm{~m}$ [1]. In these cases there is a real threat of extreme currents occurrence, flooding of coastal areas and destruction of shore facilities.

The study of seiche-like fluctuations in the Sea of Azov using mathematical modeling method and taking into account the data of field observations was performed in works [2, 3]. In [2] with the finite element method the values of periods and structures of the first six free fluctuation modes were found. In [3] seiche fluctuations of the Sea of Azov level and currents, occurred as a result of 1 $\mathrm{m}$ positive surges on the open boundary, had been researched within the framework of two-dimensional mathematic model.

In the given work physical regularities of free liquid fluctuations in the Sea of Azov basin are analyzed using a non-linear three-dimensional numerical model. Spatial characteristics of seiche-like fluctuations, location of nodal lines and velocities of occurring currents are studied. 


\section{Formulation of the problem. Boundary and initial conditions}

Mathematical model is based on the equation system of viscous fluid turbulent motion [4-6] written in the Cartesian coordinate system where $x$ axis is directed to the East, $y$ - to the North, $z$ - vertically upwards:

$$
\begin{gathered}
\frac{d u}{d t}-f v+\frac{1}{\rho} \frac{\partial p}{\partial x}=2 \frac{\partial}{\partial x}\left(A_{M} \frac{\partial u}{\partial x}\right)+\frac{\partial}{\partial y} A_{M}\left(\frac{\partial v}{\partial x}+\frac{\partial u}{\partial y}\right)+\frac{\partial}{\partial z} K_{M} \frac{\partial u}{\partial z}, \\
\frac{d v}{d t}+f u+\frac{1}{\rho} \frac{\partial p}{\partial y}=2 \frac{\partial}{\partial y}\left(A_{M} \frac{\partial v}{\partial y}\right)+\frac{\partial}{\partial x} A_{M}\left(\frac{\partial v}{\partial x}+\frac{\partial u}{\partial y}\right)+\frac{\partial}{\partial z} K_{M} \frac{\partial v}{\partial z}, \\
\frac{\partial p}{\partial z}+g \rho=0, \\
\frac{\partial u}{\partial x}+\frac{\partial v}{\partial y}+\frac{\partial w}{\partial z}=0 .
\end{gathered}
$$

Here $u, v, w$ are the velocity projections on $x, y, z$ axes; $t$ is time; $p$ is pressure; $\rho$ is density; $g$ is a free fall acceleration; $f$ is the Coriolis parameter; $d / d t=\partial / \partial t+$ $+u \partial / \partial x+v \partial / \partial y+w \partial / \partial z$ is a total derivative. The parameterization of the vertical viscosity $K_{M}$ is performed in accordance with the Mellor - Yamada semi-empirical differential model [7]. The coefficient of vertical viscosity $A_{M}$ is calculated with the usage of subgrid viscosity model [8] depending on the horizontal velocity gradients.

Boundary conditions on the free surface are of the following form:

$$
\left.w\right|_{z=\zeta}=\frac{\partial \zeta}{\partial t}+u \frac{\partial \zeta}{\partial x}+v \frac{\partial \zeta}{\partial y},\left.\quad K_{M}\left(\frac{\partial u}{\partial z}, \frac{\partial v}{\partial z}\right)\right|_{z=\zeta}=\left(\tau_{0 x}, \tau_{0 y}\right),
$$

where $\zeta(x, y, t)$ is a free surface profile; $\tau_{0 x}=C_{a} W_{x}|\mathbf{W}|$ and $\tau_{0 y}=C_{a} W_{y}|\mathbf{W}|$ are the projections of the tangential wind stresses, $\mathbf{W}$ is a wind velocity vector at a height of $10 \mathrm{~m}$ over the sea level, $C_{a}$ is an empirical coefficient of the surface friction [9] which varies depending on the wind velocity:

$$
10^{3} C_{a}=\left\{\begin{array}{cr}
2.5, & |\mathbf{W}|>22 \mathrm{~m} / \mathrm{c}, \\
0.49+0.065|\mathbf{W}|, & 8 \leq|\mathbf{W}| \leq 22 \mathrm{~m} / \mathrm{c}, \\
1.2, & 4 \leq|\mathbf{W}| \leq 8 \mathrm{~m} / \mathrm{c}, \\
1.1, & 1 \leq|\mathbf{W}| \leq 4 \mathrm{~m} / \mathrm{c} .
\end{array}\right.
$$

Boundary conditions in near-bottom layers have the following form [6]

$$
\left.\left(w+u \frac{\partial H}{\partial x}+v \frac{\partial H}{\partial y}\right)\right|_{z=-H}=0,\left.\quad K_{M}\left(\frac{\partial u}{\partial z}, \frac{\partial v}{\partial z}\right)\right|_{z=-H+h_{0}}=\left(\tau_{1 x}, \tau_{1 y}\right),
$$


where $\tau_{1 x}=C_{\mathrm{b}} u \sqrt{u^{2}+v^{2}} ; \tau_{1 y}=C_{\mathrm{b}} v \sqrt{u^{2}+v^{2}}, C_{\mathrm{b}}$ - the coefficient of bottom friction, bottom friction coefficient, which is found from the $C_{\mathrm{b}}=k^{2} /\left(\ln ^{2} h_{\mathrm{b}} / z_{0}\right)$ formula, $h_{\mathrm{b}}$ is a vertical step in the bottom layer, $z_{0}=0.003 \mathrm{~m}-$ roughness parameter characterizing hydrodynamic properties of underlying bottom surface, $z_{0}$ is determined by means of the Grant - Madsen theory [10], which describes the mechanism of wave effect on the near-bottom layer currents. The conditions of adherence are satisfied on the lateral boundaries.

The conditions of absence of liquid motion and free surface horizontality before the start of atmospheric perturbation effect are accepted as the initial (with $t=0)$ :

$$
u(x, y, z, 0)=0, \quad v(x, y, z, 0)=0, \quad w(x, y, z, 0)=0, \quad \zeta(x, y, z, 0)=0 .
$$

To construct the numerical algorithm the POM (Princeton Ocean Model) [6] model, adapted to conditions of the Sea of Azov basin [11], was used. Selection of integration steps for temporal and spatial coordinates is performed in accordance with a stability criterion for barotropic waves [12]. The bottom topography was interpolated at the model grid using the depths array, which was given on navigation charts. Its resolution by latitude and longitude is $1 / 59 \times 1 / 84^{\circ}$. At the same time the linear dimension of a cell are $\Delta x=\Delta y=1,4 \mathrm{~km}$, the number of horizontal grid nodes is $276 \times 176$, there are 11 calculated levels along the vertical. The equation had been integrated according to time with $\Delta t=18$ step to find the averaged two-dimensional components of level and velocity, and also with $\Delta t_{A}=$ $=10 \Delta t=3 \mathrm{~min}$ step - to calculate the deviation from the found middle and vertical velocity components.

Atmospheric perturbations are the main source of seiche generation in the Black Sea-Azov region [1]. Under the impact of the wind with steady direction and velocity the currents and level increase occur at one coast and level decrease at another. Upon the termination of wind impact free wave fluctuations of liquid on the sea surface take place.

Using the results of numerical experiments, performed on the basis of the above mentioned hydrodynamical model, liquid motion in the Sea of Azov basin after the stationary wind termination is studied. From $t=0$ the initially undisturbed surface is affected by the eastern wind, which velocity increases up to $20 \mathrm{~m} / \mathrm{s}$ constant value during the first 3 hours. After the setting of currents $\left(t_{\mathrm{st}}=48 \mathrm{~h}\right)$ wind velocity linearly decreases down to 0 during 3 hours $\left(t_{0}=51 \mathrm{~h}\right)$. The condition of liquid motion reaching the steady regime is determined by the fact that there are no sufficient level and current velocity (under $5 \%$ ) deviations between two adjacent values.

\section{Analysis of numerical experiment results}

To obtain the conclusions about physical regularities of free fluctuations, which occur after the termination of the abovementioned wind impact, we will analyze the results of numerical experiments.

Sea level isolines in different moments of time are represented in Fig. 1. At the initial period level surface is a single-node seiche. In the steady mode (Fig. 1, a) 
along the eastern coast occur a level decrease (positive surge) and a level increase along the western (negative surge). Nodal (dashed) line crosses the central part of the sea, it is oriented perpendicular to the wind direction. We should notice that the most intensive decreases take place in the eastern part of the sea - in the Taganrog Bay, and the highest increase - in the western part. The lowest amplitudes of level fluctuations take place in the central part of the sea.

After the termination of wind effect (Fig. 1, $b-f$ ) it occurs a significant change of equal level lines and nodal line arrangement over the time. At the moment of wind effect termination (Fig. 1, b) the nodal line didn't shift and the positive surge and negative surge zones stayed at the same areas of the sea as in steady mode. At the same time, positive surge and negative surge values decrease. In Fig. 1, $c$ it is shown that 3 hours after the wind effect termination nodal line is turned relative to the central part of the sea and is oriented in the zonal direction. The positive surge and negative surge areas had been also moving to the West, towards the existing wind. At the Taganrog Bay 3 hours later wind termination affected the level changes insufficiently.

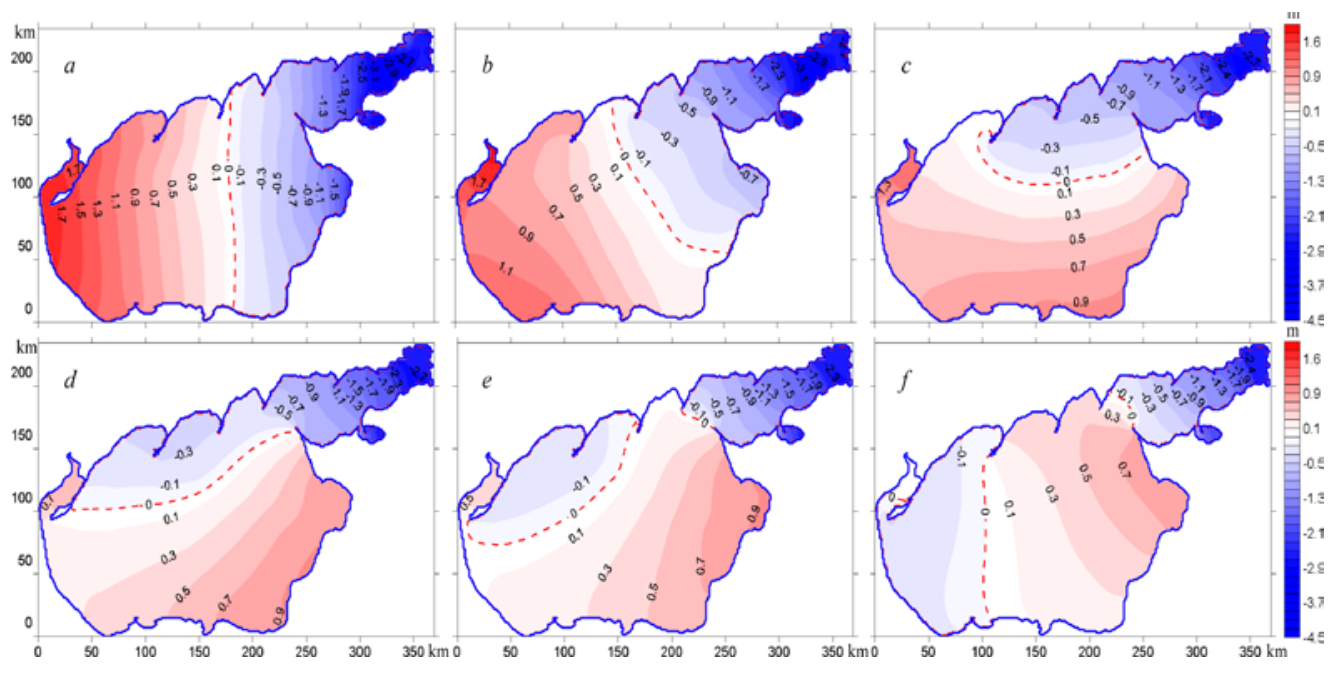

Fig. 1. Isolines of the Sea of Azov level under the steady motion $(a)$, at the moment of wind effect termination $(b)$, in 3 hours $(c)$, in 6 hours $(d)$, in 9 hours $(e)$, in 12 hours $(f)$

6 hours later (Fig. 1, d) a further movement of nodal line to the East takes place. Positive surge and negative surge areas move to the South and to the North respectively and their sizes sufficiently reduce. In the Fig. $1, e, f$ the sea level isolines for 9 and 12 hours after the wind effect termination are represented. It is obvious that free fluctuations in the given moments have two-node seiche form.

Changes of level fluctuation with time in any point of the Sea of Azov are a seiches superposition of different modes, which forming is affected by number of factors. Using the results of numerical modeling we are to perform the analysis of seiche fluctuation periods and amplitudes analysis in the points of the central part of the basin and in its coastal part. 
In table 1 extrema of seiche-like fluctuations $\left(\zeta_{k} ; k=\overline{1.4}\right)$ in the area of the Sea of Azov coast stations and their first passage time $\left(t_{k}\right)$ are represented. From the analysis of the given data it follows that the greatest positive surge, generated by eastern wind, takes place at Genichesk station $(2 \mathrm{~m})$. After the total wind effect weakening it occurs a monotonous level reduction down to the minimum value $\left(\zeta_{1}=-0.27 \mathrm{~m} ; t=9.5 \mathrm{~h}\right)$. Besides, the fluctuation amplitude from the stationary positive surge is $2.3 \mathrm{~m}$. With $t=16.5 \mathrm{~h}$ the level increase up to $0.33 \mathrm{~m}$ is observed. Amplitude of the second fluctuation $(0.6 \mathrm{~m})$ is 3.8 times smaller, than the amplitude of the first one (by $1.63 \mathrm{~m}$ ). An extreme value during the next fluctuation $(-0.12 \mathrm{~m})$ occurs in $8.2 \mathrm{~h}(24.7 \mathrm{~h})$, its $0.45 \mathrm{~m}$ amplitude $0.45 \mathrm{~m}$ differs little from the amplitude of the previous one (by $0.15 \mathrm{~m}$ ). Maximum of the fourth free fluctuation $\zeta_{4}=0.12$ occurs in $t_{4}=32.7 \mathrm{~h}$, its $0.24 \mathrm{~m}$ swing is twice as little as previous one and 9.6 times smaller than the first one.

Table 1. Stationary surge phenomena $\left(\zeta_{\mathrm{st}} \mathrm{cm}\right)$ caused by the effect of steady eastern wind with $20 \mathrm{~m} / \mathrm{s}$ velocity, first passage time $\left(t_{k}, \mathrm{~h}\right)$ and seiche-like extrema $\left(\zeta_{k}, k=\overline{1.4}\right)$, arising in the Sea of Azov coastal zone after the wind effect termination.

\begin{tabular}{l|r|r|r|r|r|r|r|r|c}
\hline Station & $\zeta_{\text {st }}$ & $\zeta_{1}$ & $t_{1}$ & $\zeta_{2}$ & $t_{2}$ & $\zeta_{3}$ & $t_{3}$ & $\zeta_{4}$ & $t_{4}$ \\
\hline Genichesk & 202 & -27 & 9.5 & 33 & 16.5 & -12 & 24.7 & 12 & 32.7 \\
Berdyansk & 25 & -57 & 2.5 & 46 & 7.7 & -8 & 17.6 & 10 & 25.6 \\
Mariupol & -153 & -1 & 12.3 & -20 & 20.2 & 17 & 27.1 & 2 & 39.2 \\
Taganrog & -158 & -89 & 24.3 & 30 & 31.5 & -8 & 41.3 & 8 & 50.4 \\
Eisk & -244 & -6 & 18.3 & 21 & 28.5 & -2 & 38.9 & 7 & 55.7 \\
P.-Akhtarsk & -175 & 92 & 5.3 & -10 & 13.9 & 34 & 21.3 & -3 & 26.7 \\
Temryuk & -18 & 103 & 2.7 & -14 & 13.5 & 25 & 18.5 & -5 & 28.5 \\
Opasnoye & 32 & 93 & 1.7 & -8 & 13.0 & 23 & 18 & -4 & 27.9 \\
Mysovoye & 98 & -20 & 8.7 & 26 & 15.4 & -6 & 24.2 & 3 & 37.3 \\
\hline
\end{tabular}

Using the results from table 1 we will perform the analysis of free fluctuation at Eisk station, where the largest negative surge is noticed $\left(-2.44 \mathrm{~m} ; t=t_{0}\right)$. The wind effect termination causes the level increase $\left(\zeta_{1}=-0.06 \mathrm{~m} ; t=18.3 \mathrm{~h}\right)$. Besides, the swing of the first fluctuation is $2.38 \mathrm{~m}$. In the future the level keeps rising and in $10.2 \mathrm{~h}$ reaches $0.21 \mathrm{~m}$ maximum value, swing of the second fluctuation $(0.27 \mathrm{~m})$ is 8.8 times smaller than the first. In another $10.4 \mathrm{~h}$ it occurs $0.23 \mathrm{~m}$ level decrease $\left(\zeta_{3}=-0.02 \mathrm{~m} ; t=38.9 \mathrm{~h}\right)$, fluctuation swing differs from the previous one by $0.04 \mathrm{~m}$. A swing of the next fluctuation $\left(\zeta_{4}=0.07 \mathrm{~m}\right)$, which takes place in $16.9 \mathrm{~h}\left(t_{4}=55.7 \mathrm{~h}\right)$ makes up $0.1 \mathrm{~m}$ and it is 23.8 times lesser than the first.

In Fig. 2 the current fields in the Sea of Azov near-surface layer in different moments of time are represented. It is obvious that in the steady motion $\left(t_{\mathrm{st}}=\right.$ $=48 \mathrm{~h}$ ) the current velocity vectra along the north-eastern coast and at the Taganrog Bay have the same direction as the wind (Fig. 2, a). In the central part of the sea there are marked out two eddy formations (of opposite signs with $100 \mathrm{~km}$ spatial scale) between which we can observe two narrow meandering streams. 
With a wind velocity decrease down to zero $\left(t=t_{0}\right)$ eddy formation process continues developing and a field of currents has the form of eddy chain (Fig. 2, $b$ ). Later a pattern of currents sufficiently changes (Fig. 2, c). Now in the whole water area the velocity vectors have the direction, which is opposite to the existing wind, velocities are greater than with $t_{\mathrm{st}}$ and there is one disturbance eddy. In 6 and 9 hours after the wind effect termination the currents remain quite intensive and they have a direction opposite to one of the stationary wind (Fig. 2, $d, e$ ). At the same time along the northern coast an anticyclonic eddy begins to form. In 12 hours (Fig. 2, $f$ ) the direction of currents from the West to the East in the Taganrog Bay retains the same, at the bay entrance occurs an anticyclonic eddy, in the central and western sea areas the currents are directed from the East to the West.
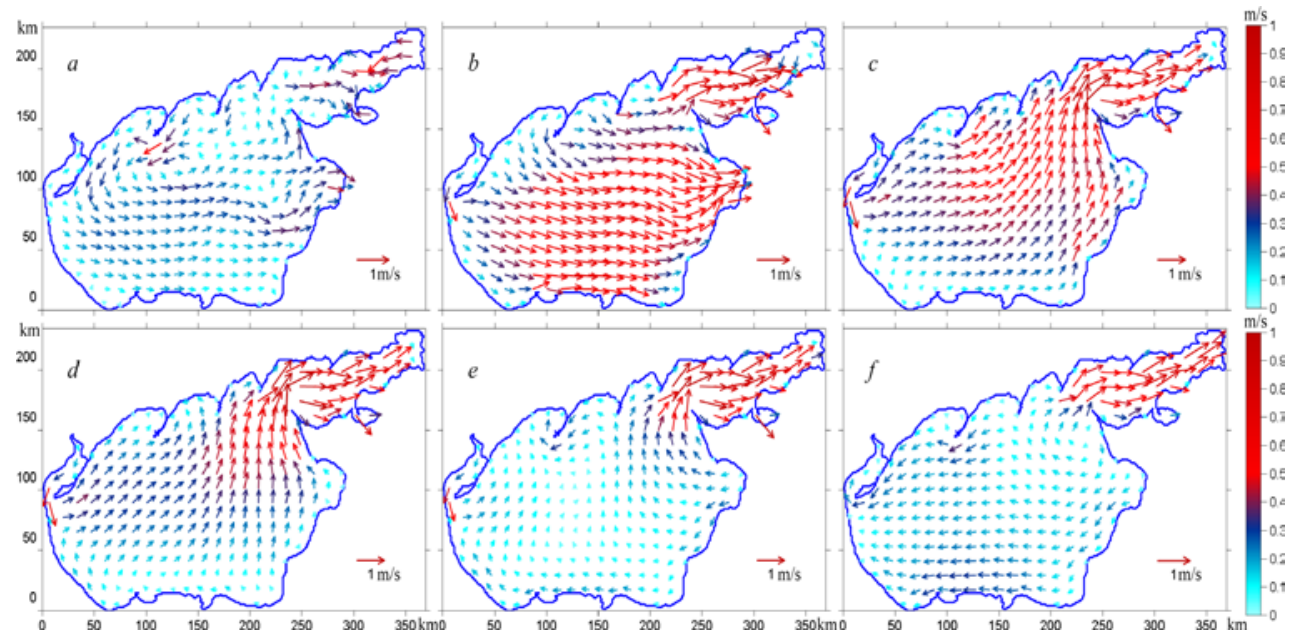

Fig. 2. Current fields of the Sea of Azov with steady motion (a), at the moment of wind effect termination $(b)$, in 3 hours $(c)$, in 6 hours $(d)$, in 9 hours $(e)$, in 12 hours $(f)$

Table 2. Extrema of seiche-like fluctiations occurring after the wind effect termination in the open part of the Sea of Azov

\begin{tabular}{c|r|r|c|r|r|r|r|r|c}
\hline Point & $\zeta_{\text {st }}$ & $\zeta_{1}$ & $t_{1}$ & $\zeta_{2}$ & $t_{2}$ & $\zeta_{3}$ & $t_{3}$ & $\zeta_{4}$ & $t_{4}$ \\
\hline$B_{0}$ & 4 & 33 & 7.7 & 2 & 14.7 & 8 & 20.6 & 2 & 29.6 \\
$B_{1}$ & -46 & 59 & 5,6 & -3 & 15.3 & 18 & 22.1 & 0 & 30.5 \\
$B_{2}$ & 5 & -37 & 1.9 & 43 & 7.4 & -3 & 17.4 & 10 & 23.9 \\
$B_{3}$ & 48 & 2 & 4.3 & 16 & 8.8 & 2 & 19.4 & 2 & 22.3 \\
$B_{4}$ & 10 & 53 & 2.8 & 1 & 13.7 & 15 & 18.5 & 0 & 28.6 \\
$B_{5}$ & -125 & 88 & 5.3 & -10 & 16.3 & 30 & 21.5 & -2 & 27.0 \\
$B_{6}$ & 10 & -52 & 1.9 & 45 & 7.4 & -7 & 17.4 & 10 & 24.7 \\
$B_{7}$ & 101 & -14 & 5.7 & 25 & 13.3 & -2 & 20.3 & 7 & 28.8 \\
$B_{8}$ & 11 & 86 & 2.5 & -8 & 13.3 & 22 & 18.3 & -3 & 28.1 \\
\hline
\end{tabular}

$\mathrm{N}$ o t e. Notations - in table 1.

To determine the seiche periods and amplitudes in the open part of the Sea of Azov the extrema of seiche-like fluctuations $(\mathrm{cm})$, occurring after the wind attenuation, and corresponding times for 9 points of the sea (Fig. 3) are given. 
From the analysis of the given data we can make a conclusion that the smallest level deviation in the steady mode of motion $(0.04 \mathrm{~m})$ is located in the amphidromic point $B_{0}\left(46.25^{\circ} \mathrm{N}, 36.46^{\circ} \mathrm{E}\right)$ - in the geometrical centre of the basin. In the points located at $50 \mathrm{~km}$ distance from the centre the level amplitudes are sufficiently higher. Thus, level deviation maxima in $B_{5}$ and $B_{7}$ points make up $1.25 \mathrm{~m}$ and $1 \mathrm{~m}$ respectively, which is 31.3 and 25.3 times greater than in $B_{0}\left(t=t_{\mathrm{st}}\right)$ point. From the comparison of maximum values - surge at Genichesk station $(2 \mathrm{~m})$ and level increase at $B_{7}$ point $(1.01 \mathrm{~m})$, negative surge at Eisk station $(2.44 \mathrm{~m})$ and level decrease at $B_{5}$ point $(-1.25 \mathrm{~m})$ it follows that the values of stationary surges and negative surges are two time higher than maximum deviations in the open part of the sea.

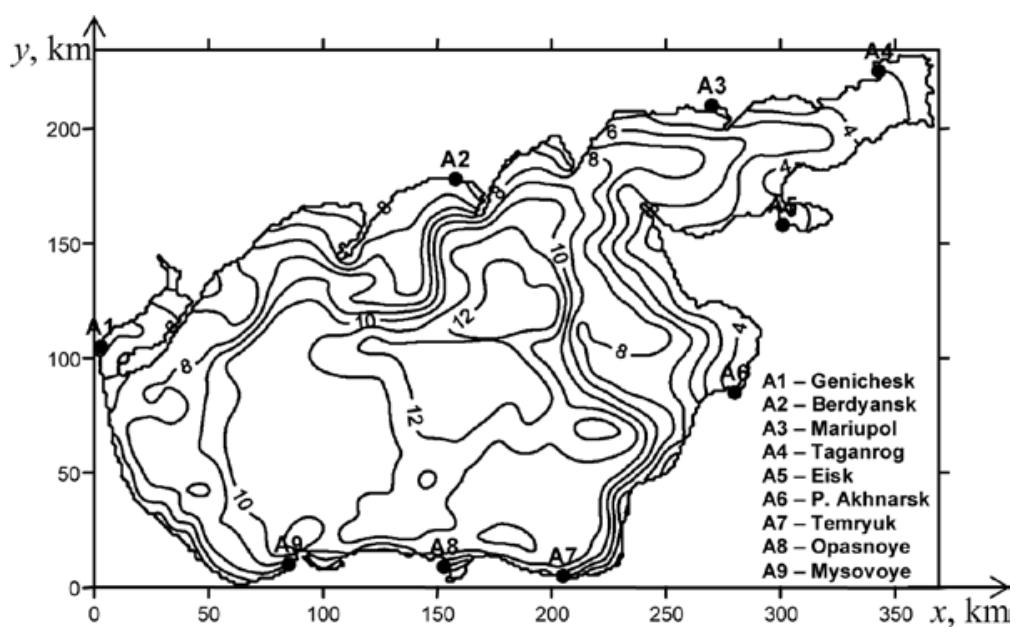

Fig. 3. Bottom relief (m) and location of $B_{0}-B_{8}$ points in the central part of the Sea of Azov

During the analysis of table 2 we should mention that the maximum sea level increase takes place in $B_{7}$ point $(1.01 \mathrm{~m})$. After a complete attenuation of wind effect it occurs a monotonic level decrease down to the minimum value $\left(\zeta_{1}=-0.14 \mathrm{~m} ; t_{1}=\right.$ $=5.7 \mathrm{~h}$ ). Besides, the fluctuation swing is $1.15 \mathrm{~m}$. In $7.6 \mathrm{~h}$ a level increase is observed $\left(\zeta_{2}=0.25 \mathrm{~m} ; t_{2}=13.3 \mathrm{~h}\right)$. The swing of the second fluctuation $(0.39 \mathrm{~m})$ is three times smaller than the swing of the first one. During the next oscillation an extreme reduction takes place in $7 \mathrm{~h}$, its 0.27 swing differs from the previous one by $0.12 \mathrm{~m}$. The next extreme level increase $\left(\zeta_{4}=0.07 \mathrm{~m}\right)$ with 0.09 swing, which is 12.7 times smaller than the previous, occurs in $8.5 \mathrm{~h}$. It is observed in $28.8 \mathrm{~h}$ after the time point $t=t_{0}$.

The greatest sea level decrease among all considered points occurs in $B_{5}(-1.25 \mathrm{~m})$, in $5.3 \mathrm{~h}$ with 2.13 swing the maximum of the first free fluctuation $\left(\zeta_{1}=0.88 \mathrm{~m}\right)$ is reached. In $11 \mathrm{~h}$ the greatest level decrease $\left(\zeta_{2}=-0.1 \mathrm{~m} ; t=16.3 \mathrm{~h}\right)$ takes place, its fluctuation swing $(0.98 \mathrm{~m})$ is 2.2 times lower than the first. The next extremum of free fluctuations is reached in $5.2 \mathrm{~h}\left(\zeta_{3}=0.3 \mathrm{~m}\right), 0.4 \mathrm{~m}$ swing is 2.5 times lower than the previous one. $\zeta_{4}=-0.02 \mathrm{~m}$ level decrease takes place in $5.5 \mathrm{~h}$ with $0.32 \mathrm{~m}$ 
swing, which is 6.7 times lower than the first. It occurs in $27 \mathrm{~h}$ after the time point $t=t_{0}$.

Height features of seiche-like fluctuations in the central part of the sea are most clearly manifested in comparison with seiche heights, which occur in coastal areas. From the analysis of table 1 and 2 data it follows that the amplitudes and swings of free fluctuations in the points of the Sea of Azov open part (table 2) are smaller than at the coastal stations. At the same time, the greatest values of level deviation in coastal and central parts of the sea in stationary mode are two times different, and extrema of seiche-like fluctuations $-1.2-2$ times. The greatest values of the first fluctuations for the positive surges at Eisk station $(2,38 \mathrm{~m})$ are 1.2 times smaller than in $B_{5}$ point $(2.13 \mathrm{~m})$, for the negative surges at Genichesk station $(2.3 \mathrm{~m})$ they are 2 times greater than in $B_{7}$ point $(1.15 \mathrm{~m})$. So, the extreme seiche fluctuation swings in the open part of the sea are comparable with free fluctuation swings in the coastal areas make 50 - $89 \%$ of swings of free fluctuations.

First passage time of natural fluctuation extrema, given in tables 1 and 2 allows us to perform a comparison of two first periods in coastal and open parts of the sea. A period of the first free fluctuation in coastal points is $15-16 \mathrm{~h}$, at Eisk station - $21 \mathrm{~h}$. Period of the second free fluctuation is $13-19 \mathrm{~h}$, at Mysovoye station - 22 h, at Eisk station - 27 h. Besides, in the central part of the Sea of Azov the first seiche-like fluctuation is performed within $13-16.5 \mathrm{~h}$, the second - within $11-17$ h. Consequently, with the exception of the stations located at complex coastlines (Fig. 3) the first seiche periods of central and coastal parts of the sea differs by $2-3 \mathrm{~h}$.

In table 3 the velocity values of stationary surficial currents $\left(|\mathbf{U}|_{\mathrm{st}}, \mathrm{cm} / \mathrm{s}\right)$, caused by steady eastern wind with $20 \mathrm{~m} / \mathrm{s}$ velocity and also the values of seichelike fluctuation currents $\left(|\mathbf{U}|_{k}, k=\overline{1.6}\right)$ in the central part of the Sea of Azov (Fig. 3) are represented. Correspondent time points $\left(t_{k}, \mathrm{~h}\right)$ are also mentioned here.

Table 3. Maximum velocities of surficial stationary currents $\left(|\mathrm{U}|_{\mathrm{st}}\right)$ caused by the steady eastern wind effect with $20 \mathrm{~m} / \mathrm{s}$ velocity, and maximum velocities of currents $\left(|\mathrm{U}|_{k}, k=\right.$ $=\overline{1.6}$ ), arising after the wind effect termination, with the corresponding time points in the central part of the Sea of Azov

\begin{tabular}{|c|c|c|c|c|c|c|c|c|c|c|c|c|c|}
\hline Point & $\begin{array}{l}|\mathrm{U}|_{\mathrm{st}}, \\
\mathrm{cm} / \mathrm{s}\end{array}$ & $\mid \begin{array}{l}|\mathrm{U}|_{1}, \\
\mathrm{~cm} / \mathrm{s}\end{array}$ & $\begin{array}{c}t_{1}, \\
\mathrm{~h}\end{array}$ & $\begin{array}{l}|\mathrm{U}|_{2}, \\
\mathrm{~cm} / \mathrm{s}\end{array}$ & $\begin{array}{c}t_{2}, \\
\mathrm{~h}\end{array}$ & $\begin{array}{l}|\mathrm{U}|_{3}, \\
\mathrm{~cm} / \mathrm{s}\end{array}$ & $\begin{array}{c}t_{3}, \\
\mathrm{~h}\end{array}$ & $\mid \begin{array}{l}|\mathrm{U}|_{4}, \\
\mathrm{~cm} / \mathrm{s}\end{array}$ & $\begin{array}{c}t_{4}, \\
\mathrm{~h}\end{array}$ & $\mid \begin{array}{l}|\mathrm{U}|_{5}, \\
\mathrm{~cm} / \mathrm{s}\end{array}$ & $\begin{array}{c}t_{5}, \\
\mathrm{~h}\end{array}$ & $\begin{array}{l}|\mathrm{U}|_{6}, \\
\mathrm{~cm} / \mathrm{s}\end{array}$ & $\begin{array}{c}t_{6}, \\
\mathrm{~h}\end{array}$ \\
\hline$B_{0}$ & 20.8 & 66.3 & 0.6 & 57.9 & 2.2 & 64.2 & 4.1 & 3.7 & 13.8 & 16.0 & 20.1 & 0.2 & 29.2 \\
\hline$B_{1}$ & 40.1 & 52.9 & 4.4 & 16.7 & 9.7 & 5.9 & 13.4 & 10.9 & 16.1 & 9.0 & 18.0 & 1.9 & 34.3 \\
\hline$B_{2}$ & 47.0 & 57.1 & 0.8 & 7.8 & 12.0 & 18.3 & 20.2 & 1.4 & 31.6 & 2.1 & 36.4 & 1.8 & 37.8 \\
\hline$B_{3}$ & 2.6 & 84.8 & 0.8 & 0.7 & 8.0 & 21.0 & 10.2 & 0.5 & 14.2 & 15.5 & 17.1 & 0.1 & 24.1 \\
\hline$B_{4}$ & 19.0 & 72.4 & 0.7 & 6.5 & 8.3 & 18.1 & 11.0 & 1.4 & 14.5 & 11.5 & 17. & 3.2 & 23.3 \\
\hline$B_{5}$ & 13.2 & 22.5 & 8.8 & 6.9 & 14.0 & 18.4 & 7.4 & 3.4 & 21.7 & 10.7 & 24.1 & 1.2 & 35.1 \\
\hline$B_{6}$ & 70.4 & 69.2 & 0.8 & 4.0 & 10.7 & 21.4 & 14.7 & 2.3 & 26.8 & 0.4 & 31.0 & 1.1 & 32.6 \\
\hline$B_{7}$ & 22.8 & 46.2 & 0.9 & 41.1 & 2.1 & 43.7 & 3.9 & 5.1 & 8.6 & 19.5 & 11.3 & 3.1 & 14.4 \\
\hline$B_{8}$ & 24.5 & 79.2 & 0.9 & 5.7 & 6.1 & 11.9 & 17.6 & 1.4 & 21.3 & 11.0 & 26.3 & 0.3 & 33.4 \\
\hline
\end{tabular}

In the area of seiche-like fluctuation nodal line (Fig. 1, b) where the vertical level fluctuations are approximate to zero, $B_{0}, B_{3}, B_{4}, B_{7}$ and $B_{8}$ points are located. 
Now we should consider some of them. From the data analysis, represented in table 3 , it follows that in $B_{0}$ point the first extreme velocity value $\left.\mathbf{U}\right|_{1}=66.3 \mathrm{~cm} / \mathrm{s} 3.2$ times exceeds the stationary velocity $|\mathbf{U}|_{\mathrm{st}}=20.8 \mathrm{~cm} / \mathrm{s}$. In 13 hours the velocity value $\left(|\mathbf{U}|_{4}=3.7 \mathrm{~cm} / \mathrm{s}\right)$ sufficiently decreases: it becomes 5.6 times smaller in comparison with $|\mathbf{U}|_{\text {st }}$ and 18 times - in comparison with $|\mathbf{U}|_{1}$. Further velocity decrease down to $1-2 \mathrm{~cm} / \mathrm{s}$ occurs in $29.2 \mathrm{~h}$. The similar velocity change takes place in point $B_{3}$. The velocity of currents in the beginning of seiche-like fluctuations $(84.8 \mathrm{~cm} / \mathrm{s})$ sufficiently exceeds the stationary motion velocity $(2.6 \mathrm{~cm} / \mathrm{s})$, and the time, during which the intensity of currents decreases down to $1 \mathrm{~cm} / \mathrm{s}$, makes up $24.1 \mathrm{~h}$.

In $B_{1}, B_{2}, B_{5}, B_{6}$ points, located at 50 and $100 \mathrm{~km}$ distance in zonal direction from amphidromic point $B_{0}$, the start of free liquid motions doesn't lead to such dramatic change of stationary velocity. We are to consider the velocity change of seiche-like fluctuations on the basis of $B_{1}$ point, which is located $50 \mathrm{~km}$ further east than $B_{0}$ point. The velocity of steady current $|\mathbf{U}|_{\text {st }}=40.1 \mathrm{~cm} / \mathrm{s}$ insufficiently differs from the first extreme value of seiche-like fluctuation velocity $\left.\mathbf{U}\right|_{1}=52.9 \mathrm{~cm} / \mathrm{s}\left(t_{1}=\right.$ $=4.4 \mathrm{~h}$ ), there is 1.3 times excess. The velocity decrease down to $2 \mathrm{~cm} / \mathrm{s}$ occurs $9-$ $12 \mathrm{~h}$ later (in $34.3 \mathrm{~h}$ ), than in nodal line zone.

From the analysis of velocity modulus values it follows that in the open sea prevail high velocities of currents, within $84.8 \mathrm{~cm} / \mathrm{s}$ (point $B_{3}$ ). At the same time the direction of surficial currents has eddy behavior with predominating meridional flow motion.

The numerical experiments using the hydrodynamical model showed that attenuation of free fluctuations in the points of the sea central part occurs faster than in coastal regions (amplitude maximum doesn't exceed $2 \mathrm{~cm}$ ). Attenuation time of liquid free fluctuations in coastal area makes $92.1 \mathrm{~h}$, which is $23.7 \mathrm{~h}$ greater than in the central part of the sea $(68.4 \mathrm{~h})$. Periods of the first fluctuation in the central and coastal parts of the Sea of Azov are also different. The maximum (by period) seiche fluctuations in coastal area (Eisk and Taganrog stations) make 20.6 and $17 \mathrm{~h}$, which is 41 and $0.8 \mathrm{~h}$ greater than in the central part of the sea (points $B_{1}$ and $\left.B_{5}\right)-15.5$ and $16.2 \mathrm{~h}$.

\section{Conclusions}

On the basis of liquid free fluctuation modeling in the Sea of Azov, which occurs after the wind effect termination, the analysis of spatial distribution physical regularities of level deviations and current velocities was performed.

Maximum values of seiche-like fluctuation swings in the coastal zone are comparable with storm surge phenomena. Besides, the altitudes of free fluctuations in the open sea part make $50-89 \%$ of the fluctuation altitudes in coastal area.

In the central part of the sea maximum velocities of currents $(84.8 \mathrm{~m} / \mathrm{s})$ during the seiche-like fluctuations exceed the velocities of stationary currents, caused by storm wind $(70.4 \mathrm{~m} / \mathrm{s})$, by $21 \%$. Thus, seiches make a significant contribution to the changeability of current velocities. 
Free level fluctuations (within $2 \mathrm{~cm}$ ) attenuate faster $(60 \mathrm{~h})$ than amplitudes of current velocities, which don't exceed $2 \mathrm{~cm} / \mathrm{s}$ and manifest themselves in 60 200 h time interval.

\section{REFERENCES}

1. Dotsenko, S.F., Ivanov, V.A., 2010, "Prirodnye katastrofy Azovo-Chernomorskogo regiona [Natural disasters of Azov-Black Sea region]”, Sevastopol, ECOSI-Gidrofizika, 174 p. (in Russian).

2. Ivanov, V.A., Manilyuk, Yu.V. \& Cherkesov, L.V., 1994, “O seyshakh Azovskogo morya [On the Sea of Azov seiches]”, Meteorologiya i gidrologiya, no. 6, pp. 105-110 (in Russian).

3. Matishov, G.G., Inzhebeikin, Yu.I., 2009, "Chislennye issledovaniya seysheobraznykh kolebaniy urovnya Azovskogo morya [Numerical research of the Sea of Azov seiche-like fluctuations]”, Okeanologiya, vol. 49, no. 4, pp. 485-493 (in Russian).

4. Setenskii, L.N., 1977, “Teoriya volnovykh dvizheniy zhidkosti”, Moscow, Nauka, 816 p. (in Russian).

5. Cherkesov, L.V., Ivanov, V.A. \& Chartiev, S.M., 1992, "Vvedenie v gidrodinamiku i teoriyu voln”, Saint Petersburg, Gidrometeoizdat, 264 p. (in Russian).

6. Blumberg, A.F., Mellor, G.L., 1987, “A description of three dimensional coastal ocean circulation model”, Three-Dimensional Coastal Ocean Models, Ed. N. Heaps., Washington, D. C., American Geophysical Union, pp. 1-16.

7. Mellor, G.L., Yamada, T., 1982, Development of a turbulence closure model for geophysical fluid problems, Rev. Geophys. Space Phys., vol. 20, no. 4, pp. 851-875.

8. Smagorinsky, J., 1963, "General circulation experiments with primitive equations, I. The basic experiment”, Mon. Wea. Rev., vol. 91, no. 3, pp. 99-164.

9. Wannawong, W., Humphries, U.W. \& Wongwises, P. [et al.], 2011, "Mathematical modeling of storm surge in three dimensional primitive equations”, Inter. Comp. Math. Sci., no. 5, pp. 44-53.

10. Grant, W.D., Madsen, O.S., 1979, "Combined wave and current interaction with a rough bottom”, J. Geophys. Res., vol. 84, pp. 1797-1808.

11. Fomin, V.V. 2002, “Chislennaya model' tsirkulyatsii vod Azovskogo morya [Numerical model of the Sea of Azov water circulation]”, Nauchnye trudy UkrNIGMI, iss. 249, pp. 246-255 (in Russian).

12. Courant, R., Friedrichs, K.O. \& Lewy, H., 1967, "On the partial difference equations of mathematical physics”, IBM J., March, pp. 215-234. 